\title{
Incidence and time trends of joint surgery in patients with psoriatic arthritis: a register-based time series and cohort study from Denmark
}

\author{
Jørgen Guldberg-Møller (ㄷ) , ${ }^{1,2}$ Rene Lindholm Cordtz () , Lars Erik Kristensen, ${ }^{4}$ \\ Lene Dreyer ${ }^{5,6}$
}

\begin{abstract}
Handling editor Josef $S$ Smolen

- Additional material is published online only. To view please visit the journal online (http://dx.doi.org/10.1136/ annrheumdis-2019-215313)
\end{abstract}

${ }^{1}$ Copenhagen University Hospital, Bispebjerg and Frederiksberg, The Parker Institute, Frederiksberg, Denmark

${ }^{2}$ Department of Rheumatology, Slagelse Sygehus, Slagelse, Denmark

${ }^{3}$ Center for Rheumatology and Spine Diseases - Gentofte Rigshospitalet, Hellerup, Denmark

${ }^{4}$ Department of Rheumatology, The Parker Institute, Frederiksberg, Denmark ${ }^{5}$ Department of Rheumatology, Aalborg University Hospital,

Aalborg, Denmark

${ }^{6}$ Department of Clinical Medicine, Aalborg University, Aalborg, Denmark

\section{Correspondence to}

Dr Jørgen Guldberg-Møller, Copenhagen University Hospital, Bispebjerg and Frederiksberg, The Parker Institute, Frederiksberg 2000, Denmark: joergen.guldberg-moeller@ regionh.dk

Received 1 March 2019 Revised 26 June 2019 Accepted 29 June 2019 Published Online First 12 July 2019

Check for updates

(C) Author(s) (or their employer(s)) 2019. No commercial re-use. See rights and permissions. Published by BMJ.

To cite: Guldberg-Møller J, Cordtz RL, Kristensen LE, et al. Ann Rheum Dis 2019;78:1517-1523.

\section{ABSTRACT}

Objective To investigate time-trends and cumulative incidence of joint surgery among patients with psoriatic arthritis (PsA) compared with the general population. Methods In this nationwide register-based cohort study, The Danish National Patient Registry was used to identify incident PsA patients. The 5-year incidence rates (IR) and incidence rate ratios (IRR) of joint surgery were calculated in four calendar-period defined cohorts. Each patient was matched with ten non-PsA individuals from the general population cohort (GPC). The cumulative incidences of any joint and joint-sacrificing surgery, respectively, were estimated using the Aalen-Johansen method.

Results From 1996 to 2017, 11960 PsA patients (mean age 50 years; $57 \%$ female) were registered. The IRR of any joint surgery was twice as high for PsA patients compared with GPCs across all calendar periods. Among patients with PsA, 2, 10 and 29\% required joint surgery at 5, 10 and 15 years after diagnosis. The risk of surgery in PsA patients diagnosed at 18-40years was higher $(22 \%)$ than in GPC 60 + year old $(20 \%)$ after 15 years of follow-up.

Conclusions The use of joint surgery among PsA patients remained around twofold higher from 1996 to 2012 compared with GPC. After 15 years of follow-up, nearly $30 \%$ of the PsA patients had received any surgery, and even a person diagnosed with PsA at the age of 18-40 years had a higher risk of surgery than GPCs of $60+$ year old. Thus, the high surgical rates represent an unmet need in the current treatment of PsA.

\section{INTRODUCTION}

In the 1970s, psoriatic arthritis (PsA) was considered a relatively benign disorder, but during recent decades it has become evident that $40 \%-60 \%$ of PsA patients will develop erosive arthritis, loss of joint architecture and associated loss of function. ${ }^{1}$ This positions PsA as a significant health concern. ${ }^{2-6}$ X-ray-assessed structural damage in joints of PsA patients appears of similar magnitude and impact as seen in patients with rheumatoid arthritis (RA). ${ }^{7}$ For patients with PsA, the mainstay of treatment is pharmacological, but surgery may ultimately be necessary for pain relief and restoration of physical function. Although conventional synthetic DMARDS are commonly prescribed for PsA, studies show marginal if any benefit concerning radiological progression. ${ }^{89}$
Key messages

What is already known about this subject?

- $40 \%-60 \%$ of patients with psoriatic arthritis (PsA) will develop erosive arthritis and jointrelated surgery may ultimately be necessary for pain relief. However, the secular trends in surgery rates must be seen in the context of trends in a general population cohort (GPC).

What does this study add?

- Using data from a large nationwide populationbased cohort of patients with PsA compared with a GPC we demonstrated that the 5-year incidence rate of joint surgery in PsA was twice as high as a matched GPC and did not change substantially from 1996 to 2012.

- Our cumulative risk analysis showed that after 15 years of follow-up, $29 \%$ of the PsA patients had received surgery.

How might this impact on clinical practice or future developments?

- Clinicians should be aware of high joint related surgical rates in the PsA population and implement a treat-to-target strategy early after diagnosis.

- Future studies will be needed to identify the impact of biological DMARD treatment on the need for surgery using individual-level based information.

- Surgical rates represent a possible treatment outcome to monitor in future studies.

The introduction of biological DMARDS (bDMARDs) has had dramatic therapeutic effects and have demonstrated an ability to retard the radiological progression of peripheral arthritis; dactylitis, enthesitis and spondylitis. ${ }^{10-13}$ It is unclear if the introduction of bDMARDS has translated into a reduced need for joint surgery as observed in RA populations as it was introduced later and more gradually in PsA. ${ }^{14-16}$ Lewinson et al found a paradoxical increase in surgery following the introduction of bDMARDs in the UK. ${ }^{16}$ Nystad et al did not detect a reduced need for surgery in Norwegian PsA patients prescribed bDMARDS and the risk of joint surgery was the same regardless if patients were diagnosed in 1985 or $1998 . .^{17}$ 
The sparse data on utilisation of joint surgery in PsA warrants a large-scale population-based study. In this nationwide register-based study, we aimed to study time-trends in the incidence of joint surgery among PsA patients compared with a general population cohort (GPC) in Denmark from 1996 to 2012, and further, we investigated the cumulative incidence of joint surgery up to 15 years after patients were diagnosed with PsA.

\section{METHODS}

\section{Study design}

We conducted a nationwide register-based study in accordance with the REporting of studies Conducted using Observational Routinely-collected Data (RECORD) - guidelines, ${ }^{18}$ investigating the 5 -year incidence rate (IR) of a first joint surgery in four calendar-period defined cohorts from 1996 to 2012, and second, we estimated the cumulative incidence of joint surgery from 1996 to 2017 in Danish PsA patients.

Accurate register-linkage is possible on an individual-based level in Denmark by using the unique central personal registry number assigned at birth or on emigration. The study period was from 1 January 1996 to 31 December 2017.

\section{Data sources}

Danish National Patient Registry

Established in 1977 and used for registration of diagnoses and surgical interventions at inpatient and outpatient (since 1995) hospital contacts. ${ }^{19}$ With every discharge, information is provided on up to 20 discharge diagnoses coded by the International Classification of Diseases (ICD; ICD-8 from 1977 to 1993, ICD-10 from 1994). Since 1996, surgeries have been coded according to the Nordic Medico-Statistical Committee (NOMESCO) system. ${ }^{20}$ The NOMESCO constitutes the first common Nordic classification of surgical procedures and is an abbreviated list of surgical procedures for Denmark, Finland, Norway and Sweden published for the first time in 1989.

\section{Civil Registration System}

The Civil Registration System (CRS) has been used for registration of deaths and migrations among all Danish citizens since $1968 .{ }^{19}$ From CRS dates of birth, emigration and death for all patients were obtained. Further, CRS was used for matching PsA patients with GPCs.

\section{Study populations}

\section{PsA patients}

All incident patients diagnosed with PsA (ICD-10: M070, M071, M072, M073, M073A, M073B) at a rheumatology or general internal medicine department at private and public hospitals in Denmark from 1996 through 2017. Prevalent PsA patients with a first diagnosis before 1996 were excluded as were patients under the age of 18 years.

\section{General population cohort}

Each incident PsA patient was matched with up to 10 non-PsA individuals from the general population of Denmark. Matching criteria were sex, year of birth and municipality. This matching was performed only once at the initial cohort identification stage, and thus no replacement matching was undertaken following subsequent patient exclusions.

\section{Outcomes}

\section{Primary outcome}

The primary outcome was the occurrence of any first joint surgery registered in Danish National Patient Registry (DNPR) (see online supplementary table S1 for surgeries and associated NOMESCO codes).

\section{Secondary outcomes}

We further dissected the primary outcome into joint sacrificing and non-joint sacrificing surgery of upper the upper extremities (shoulder, elbow and wrist/hand) and the lower extremities (hip, knee and ankle/foot). We defined joint sacrificing surgery as arthroplasty and arthrodesis and non-joint sacrificing surgery as soft tissue, synovial surgery or joint surfaces, mainly synovectomies. Finally, we investigated total hip arthroplasty (THA) and total knee arthroplasty (TKA) as individual outcomes due to the high frequency and costs, and classification as major surgery.

\section{Statistics}

Time-trends in surgery

Incident PsA patients from 1996 to 2012 were grouped into cohorts according to predefined calendar periods of diagnosis: 1996-2000; 2001-2004; 2005-2008; 2009-2012). Within each calendar cohort, the 5-year age-standardised and sex-standardised IR with 95\% CIs of joint surgery was calculated. Patients diagnosed between 2013 and 2017 could not be followed up for a full 5 years and were not included in the time

Table 1 Baseline characteristics and demographics of incident psoriatic arthritis (PsA) patients and a matched general population cohort (GPC) according to calendar period of diagnosis

\begin{tabular}{|c|c|c|c|c|c|c|c|c|c|c|}
\hline & \multicolumn{2}{|l|}{$1996-2000$} & \multicolumn{2}{|l|}{ 2001-2004 } & \multicolumn{2}{|l|}{$2005-2008$} & \multicolumn{2}{|l|}{ 2009-2012 } & \multicolumn{2}{|l|}{ 2013-2017* } \\
\hline & PsA & GPC & PsA & GPC & PsA & GPC & PsA & GPC & PsA & GPC \\
\hline Individuals (n) & 1635 & 16020 & 1548 & 15180 & 2466 & 24298 & 3041 & 29939 & 3270 & 23859 \\
\hline $\begin{array}{l}\text { Age in years, median } \\
\text { (IQR) }\end{array}$ & $\begin{array}{l}48.6 \\
(38.9,56.3)\end{array}$ & $\begin{array}{l}48.3 \\
(38.7,55.8)\end{array}$ & $\begin{array}{l}49.8 \\
(38.8,58.1)\end{array}$ & $\begin{array}{l}49.4 \\
(38.6,57.8)\end{array}$ & $\begin{array}{l}49.5 \\
(39.7,58.4)\end{array}$ & $\begin{array}{l}49.4 \\
(39.7,58.4)\end{array}$ & $\begin{array}{l}50.0 \\
(39.8,59.6)\end{array}$ & $\begin{array}{l}49.8 \\
(39.7,59.3)\end{array}$ & $\begin{array}{l}52.1 \\
(41.4,62.1)\end{array}$ & $\begin{array}{l}51.6 \\
(41.2,61.4)\end{array}$ \\
\hline Female sex, n (\%) & $918(56.1)$ & $8967(56.0)$ & $843(54.5)$ & $8299(54.7)$ & $1381(56.0)$ & $13623(56.1)$ & $1796(59.1)$ & $17720(59.2)$ & $1862(56.9)$ & $13598(57.0)$ \\
\hline CVD, n (\%) & $64(3.9)$ & $608(3.8)$ & $100(6.5)$ & $673(4.4)$ & $147(6.0)$ & $1126(4.6)$ & $205(6.7)$ & $1357(4.5)$ & $202(6.2)$ & $1108(4.6)$ \\
\hline COPD, n (\%) & $21(1.3)$ & $237(1.5)$ & $28(1.8)$ & $295(1.9)$ & $56(2.3)$ & $392(1.6)$ & $74(2.4)$ & $454(1.5)$ & $93(2.8)$ & $382(1.6)$ \\
\hline Depression, n (\%) & $12(0.7)$ & $51(0.3)$ & $22(1.4)$ & $127(0.8)$ & $39(1.6)$ & $246(1.0)$ & $50(1.6)$ & $394(1.3)$ & $78(2.4)$ & 385 (1.6) \\
\hline IBD, n (\%) & $14(0.9)$ & $52(0.3)$ & $15(1.0)$ & $85(0.6)$ & $20(0.8)$ & $142(0.6)$ & $28(0.9)$ & $177(0.6)$ & $41(1.3)$ & $138(0.6)$ \\
\hline Diabetes, n (\%) & $33(2.0)$ & $213(1.3)$ & $59(3.8)$ & $278(1.8)$ & $82(3.3)$ & $509(2.1)$ & $105(3.5)$ & $665(2.2)$ & $157(4.8)$ & $546(2.3)$ \\
\hline Uveitis, n (\%) & $8(0.5)$ & $15(0.1)$ & $15(1.0)$ & $40(0.3)$ & $11(0.4)$ & $45(0.2)$ & $24(0.8)$ & $49(0.2)$ & $39(0.2)$ & $33(1.0)$ \\
\hline
\end{tabular}

* Only included in the analysis of the cumulative incidence of surgery as patients diagnosed in this period did not have a full 5 years of follow-up.

COPD, chronic obstructive pulmonary disease; CVD, cardiovascular disease; IBD, inflammatory bowel disease. 


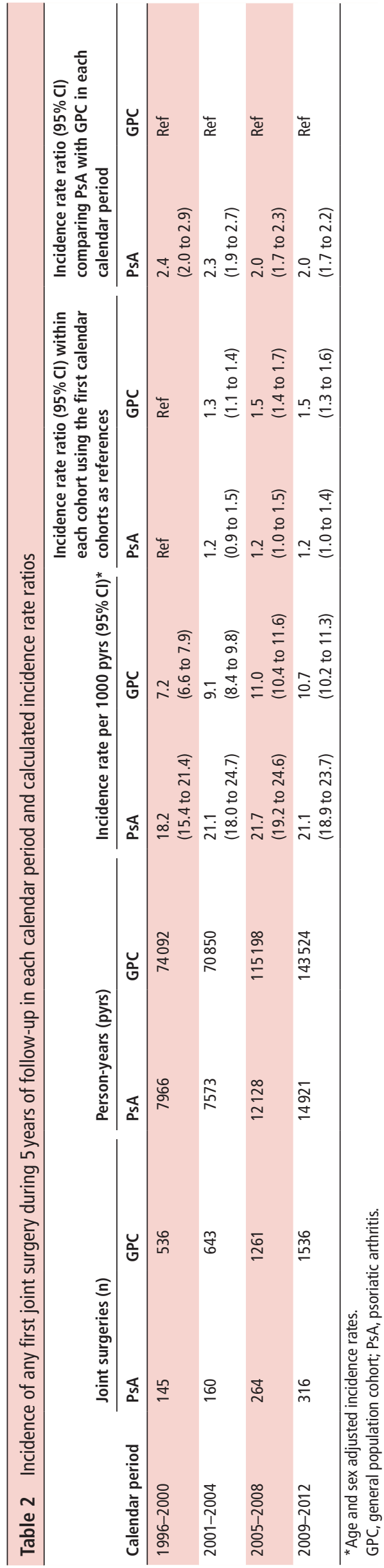

trends analysis. We subsequently calculated incidence rate ratios (IRR) internally for the PsA calendar cohorts using the 5-year age and sex-standardised IR with the 1996-2000 PsA cohort as a reference. The same calculations were carried out for the corresponding GPC calendar cohorts. We furthermore compared the IR of surgery among PsA patients and GPC within each calendar period of interest by calculating IRRs with GPC as a reference in each calendar period. In the individual analysis patients and GPCs could only contribute with one event, the first surgery.

\section{Cumulative incidence}

The cumulative incidence of any first joint surgery was estimated in all PsA patients diagnosed, and GPCs matched between 1996 and 2017. For this, we used the Aalen-Johansen estimator. ${ }^{21}$ In these analyses, patients and GPCs were followed up from date of diagnosis to the time of any first joint surgery, death, emigration, or end of 2017, whichever occurred first.

In a secondary analysis, we estimated the cumulative incidence of a first joint sacrificing surgery. Lastly, the age-specific cumulative incidence proportion of any joint, joint and non-joint sacrificing surgery was estimated stratified by age at diagnosis (18-40, 40-60, 60+ years).

\section{RESULTS}

In total, 11960 PsA patients and 109296 GPCs (mean age for PsA 50.0 years and 49.6 for GPC; $57 \%$ female in both groups) were identified between 1996 and 2017 (table 1).

The number of incidents PsA patients doubled from 20012004 to 2013-2017. A higher proportion of patients with PsA suffered from comorbidities compared with GPC across all calendar periods, and the proportion of PsA patients with comorbidities increased from 1996 to 2012.

\section{Time-trends in joint surgery}

Table 2 shows the 5 -year IR of any joint surgery in patients diagnosed with PsA within each calendar period compared with GPC. The IR of surgery was doubled in the PsA population in all calendar periods ranging from 18.2 (15.4-21.4) surgeries to 21.7 (19.2-24.6) surgeries per 1000 pyrs. The IRR of a first joint surgery was twice as high for PsA patients compared with GPCs across all calendar periods.

Similarly, the overall IR of joint and non-joint sacrificing surgery was $10.7(9.8-11.7)$ and $13.0(12.0-14.2)$ per 1000 pyrs, respectively in the PsA population compared with an overall IR of 3.7 (3.5-3.9) and 7.0 (6.8 to 7.3) in GPC from 1996 to 2012. The IR of non-joint sacrificing surgery was higher than joint sacrificing surgery within the PsA group except in 2001-2004. The increase in joint sacrificing surgery from 2001 to 2004 is also reflected in higher IR of THA and TKA among PsA patients during that period (online supplementary figure S1).

The IR of surgery to the lower extremities was higher than for upper extremities in both PsA and GPC cohorts for all calendar periods (online supplementary figure S2).

\section{Cumulative incidence of surgery}

The cumulative incidence proportion of any joint surgery was 1.7 (1.4-2.0), $10.4(9.6-11.2)$ and $28.9 \%(27.2-30.6)$ among PsA patients after 5,10 and 15 years of disease duration, respectively. Among GPCs, the corresponding proportions were 0.5 $(0.5-0.6), 4.6(4.5-4.8)$ and $14.6 \%(14.2-15.1)$ at 5,10 and 15 years of follow-up (figure 1). A similar increased cumulative incidence of joint sacrificing surgery (figure 1) was observed at all timepoints. The proportion of PsA patients who had THA and 
Cumulative risk of any first joint surgery (solid lines) and any first joint-sacrificing surgery (dotted lines)

among patients with psoriatic arthritis and matched general population controls

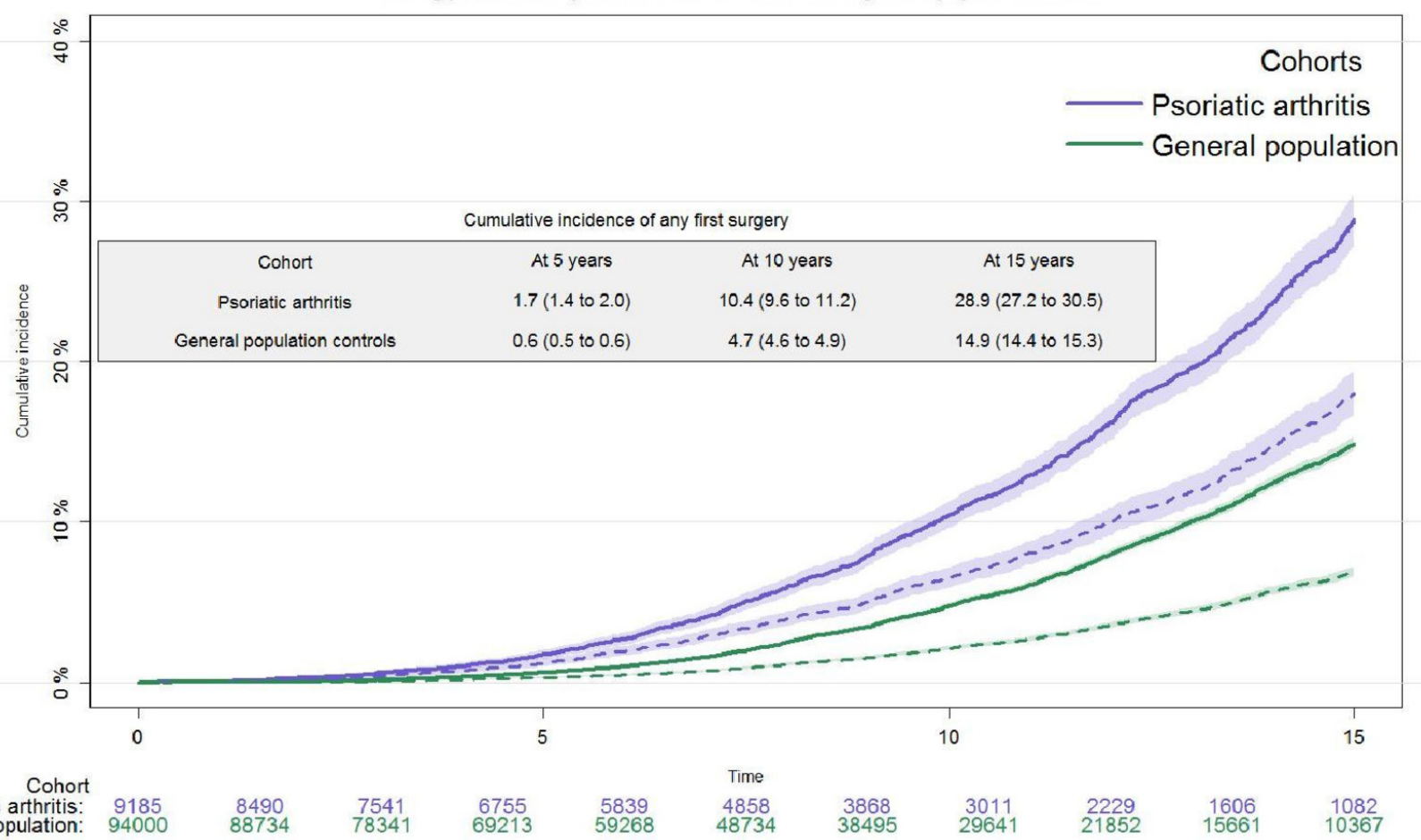

Figure 1 Cumulative incidence proportion of any first joint surgery (solid lines) and first joint-sacrificing surgery (dotted lines) among patients with psoriatic arthritis and matched general population controls using the Aalen-Johansen estimator.

TKA 15 years following diagnosis were 6.7 (5.8-7.6) and 6.9\% (6.0-7.8).

The cumulative incidence of any joint related surgery stratified by age categories at PsA diagnosis (figure 2) showed that at 15 years of follow-up all age strata of PsA patients were of higher risk of surgery than any GPC age strata. Notably, the risk of surgery in PsA patients diagnosed at $18-40$ years was higher than in GPC $60+$ yearold after 15 years of follow-up, 22.4 (19.3-25.6) and 19.9\% (18.7-20.9), respectively.

Already after 5 years of follow-up, the cumulative incidence of joint sacrificing surgery among PsA patients was almost higher in the age group of 40-60 years $1.2 \%(0.9-1.6)$

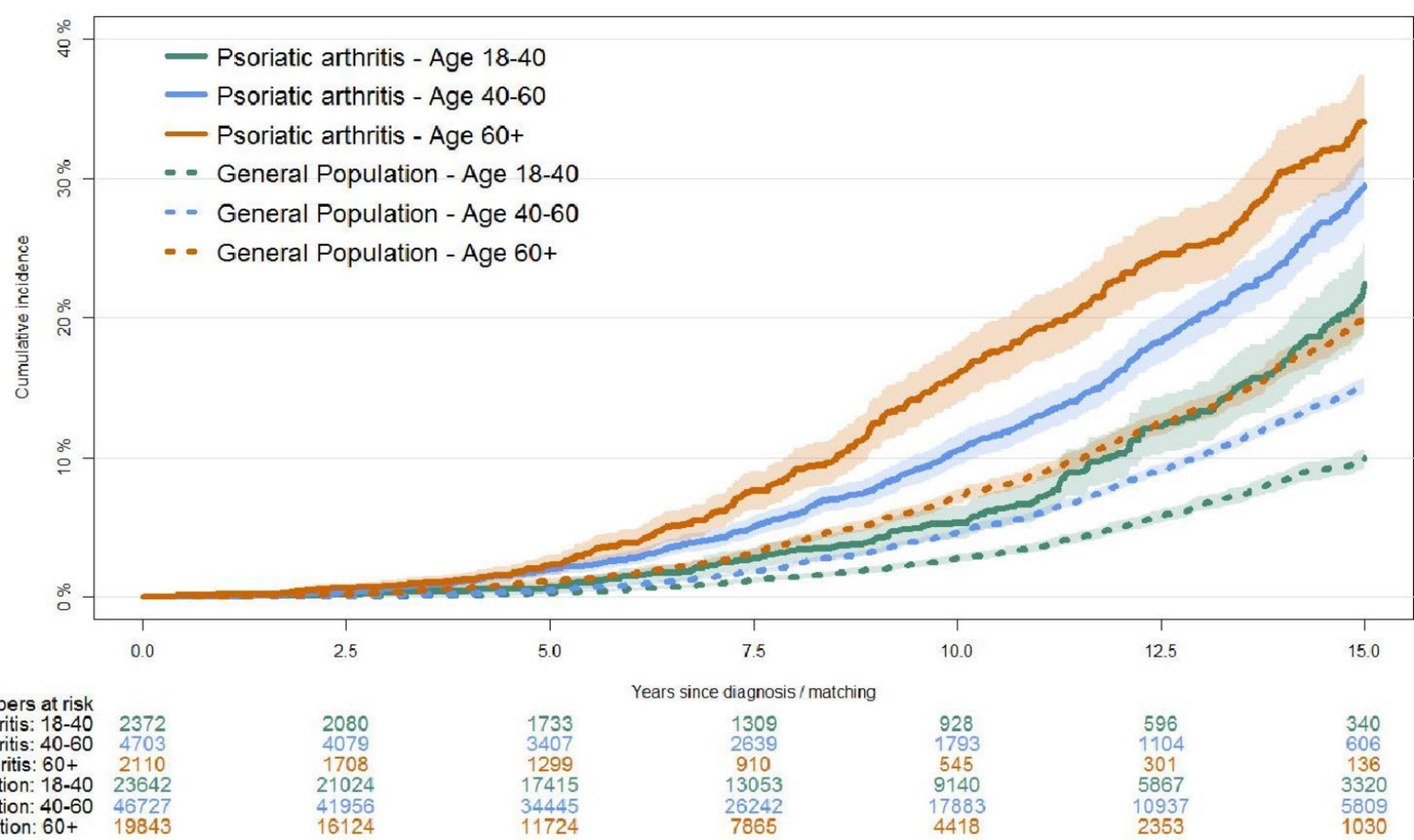

\begin{tabular}{|c|c|c|c|c|c|c|c|}
\hline \multirow[b]{2}{*}{$\begin{array}{l}\text { Numbers at risk } \\
\text { Psoriatic arthritis: } 18-40 \\
\text { Psoriatic arthritis: } 40-60 \\
\text { Psoriatic arthritis: } 60+ \\
\text { General Population: } 18-40 \\
\text { General Population: } 40-60 \\
\text { General Population: } 60+\end{array}$} & \multicolumn{7}{|c|}{ 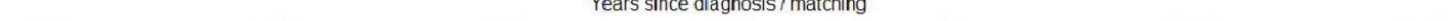 } \\
\hline & $\begin{array}{l}2372 \\
4703 \\
2110 \\
23642 \\
46727 \\
19843\end{array}$ & $\begin{array}{l}2080 \\
4079 \\
1708 \\
21024 \\
41956 \\
16124\end{array}$ & $\begin{array}{c}1733 \\
3407 \\
1299 \\
17415 \\
34445 \\
11724\end{array}$ & $\begin{array}{c}1309 \\
2639 \\
910 \\
13053 \\
26242 \\
7865\end{array}$ & $\begin{array}{c}928 \\
1793 \\
545 \\
9140 \\
17883 \\
4418\end{array}$ & $\begin{array}{c}596 \\
1104 \\
301 \\
5867 \\
10937 \\
2353\end{array}$ & $\begin{array}{c}340 \\
606 \\
136 \\
3320 \\
5809 \\
1030\end{array}$ \\
\hline
\end{tabular}

Figure 2 Cumulative incidence of any joint surgery during follow-up according to age strata of $18-40$ years, 40-60 years and 60+ years at the time of psoriatic arthritis diagnosis (solid lines) compared with age-matched general population cohort (dotted lines). 

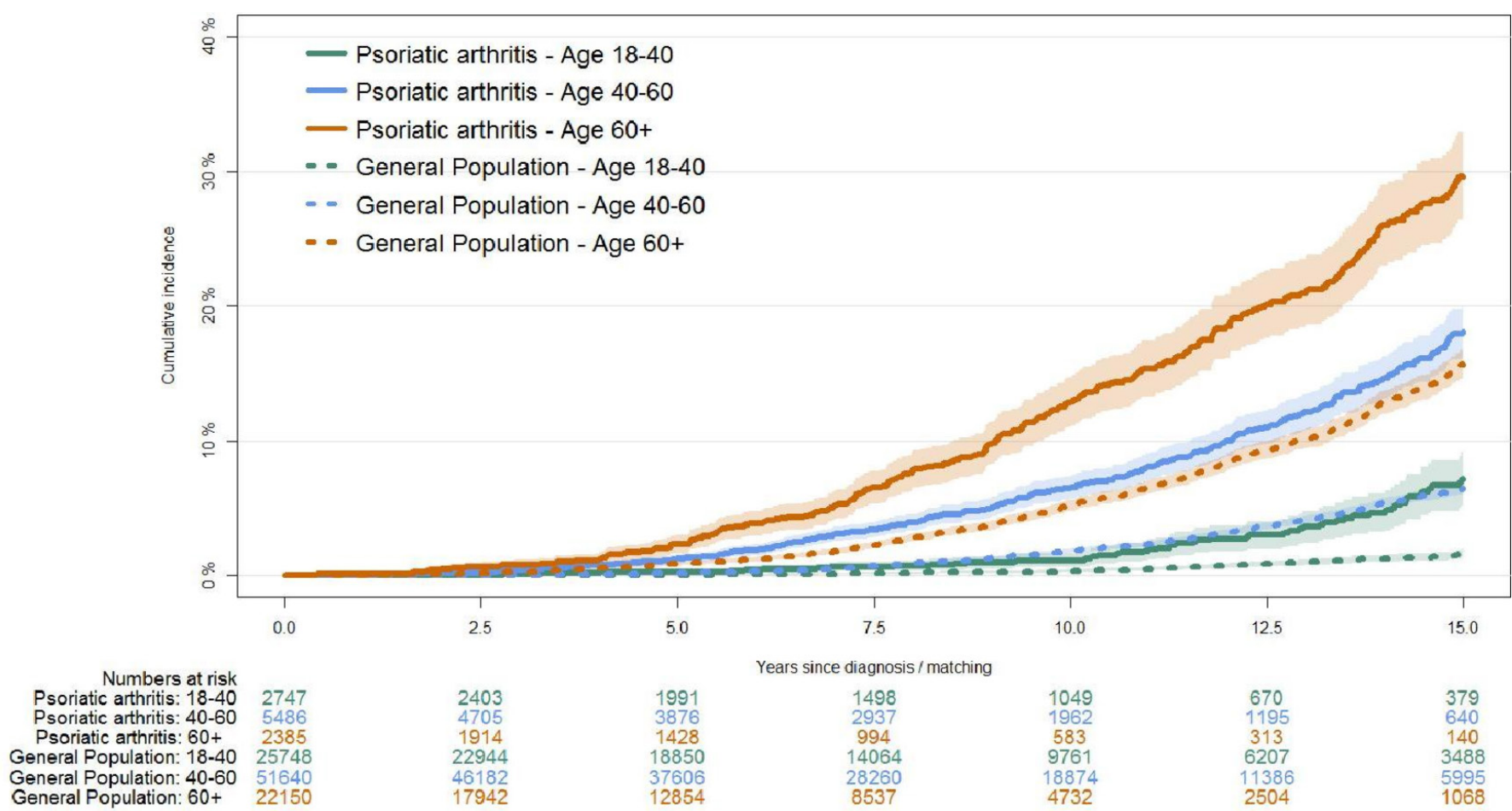

Figure 3 Cumulative incidence of joint sacrificing surgery over time according to age strata of 18-40 years, $40-60$ years and 60+ years at the time of psoriatic arthritis diagnosis (solid lines) compared with age-matched general population cohort (dotted lines).

compared with GPC at $60+0.9 \%(0.7-1.0)$ (figure 3). For the young age group $18-40$ years the relative difference in joint sacrificing surgery was 7.1 (5.2-9.1) in PsA against 1.6\% (1.3-2.0) in GPC. The highest cumulative incidence of THA and TKA was found in PsA patients diagnosed at $60+$ years compared with all other groups (online supplementary figures
S3 and S4). PsA patients diagnosed age 40-60 years the risk of TKA 7.2 (5.9-8.6) was higher than GPC matched at age $60+5.6(5.0-6.3)$.

After 15 years of disease duration, all PsA patients age groups were at higher risk of non-joint sacrificing surgery compared with any age group of GPCs (figure 4).

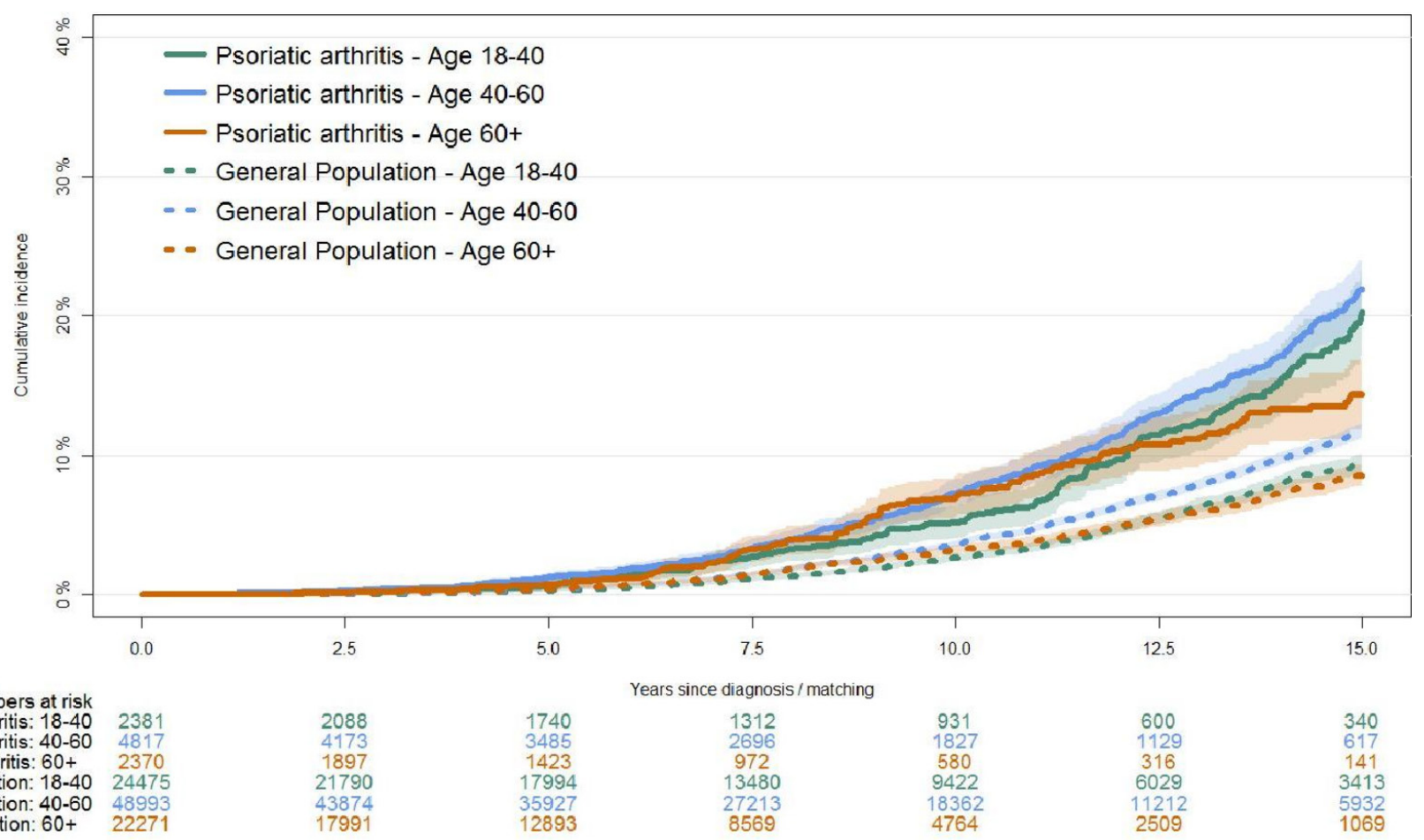

\begin{tabular}{|c|c|c|c|c|c|c|c|}
\hline \multirow[b]{2}{*}{$\begin{array}{r}\text { Numbers at risk } \\
\text { Psoriatic arthritis: } 18-40 \\
\text { Psoriatic arthritis: } 40-60 \\
\text { Psoriatic arthritis: } 60+ \\
\text { General Population: } 18-40 \\
\text { General Population: } 40-60 \\
\text { General Population: } 60+\end{array}$} & \multicolumn{7}{|c|}{ fears simle aragnosis / matering } \\
\hline & $\begin{array}{l}2381 \\
4817 \\
2370 \\
24475 \\
48993 \\
22271\end{array}$ & $\begin{array}{c}2088 \\
4173 \\
1897 \\
21790 \\
43874 \\
17991\end{array}$ & $\begin{array}{c}1740 \\
3485 \\
1423 \\
17994 \\
35927 \\
12893\end{array}$ & $\begin{array}{c}1312 \\
2696 \\
972 \\
13480 \\
27213 \\
8569\end{array}$ & $\begin{array}{c}931 \\
1827 \\
580 \\
9422 \\
18362 \\
4764\end{array}$ & $\begin{array}{c}600 \\
1129 \\
316 \\
6029 \\
11212 \\
2509\end{array}$ & $\begin{array}{l}340 \\
617 \\
141 \\
3413 \\
5932 \\
1065\end{array}$ \\
\hline
\end{tabular}

Figure 4 The cumulative incidence of non-joint sacrificing surgery over time according to age strata of 18-40 years, 40-60 years and 60+ years at the time of psoriatic arthritis diagnosis (solid lines) compared with age-matched general population cohort (dotted lines). 


\section{DISCUSSION}

In this nationwide cohort study of PsA patients, we demonstrated an almost constant 5-year IR in any joint surgery from 1996 to 2012 . The trend of surgery was almost similar to that of the GPC but with more than twice as high rates among PsA patients at any time point. The cumulative incidence of surgery was much higher in PsA patients, and almost 30\% received joint surgery after 15 years of disease duration compared with $15 \%$ among GPCs. Even a person diagnosed with PsA between the age of $18-40$ years had a higher risk of surgery than a non-PsA $60+$ year old after 15 years of follow-up. The 5 -year IR of joint surgery in the Danish PsA population remained high opposed to a decrease in incidence in a Danish RA population in the bDMARD era. ${ }^{14}$

It is a puzzle why surgical rates remain high in PsA. Evidence exists that bDMARDs has been less aggressively implemented in PsA, ${ }^{22}$ and an intensive treat-to-target strategy have been much harder to exercise due to the heterogeneous nature of the disease and adherence to different composite measures of disease activity. This lack of strict guidelines may offer some explanation of why an efficacious treatment introduced at a national level in Denmark only show a yearly treatment initiation of 118 patients on average. ${ }^{16}$ Hopefully, the benefits of the treatment have yet to come and treat-to-target strategies have emerged, ${ }^{23}$ and gradually sees implementation. It can also be speculated that the choice of surgery is decided more on subjective markers of disease such as Visual Analogue Scale-pain and tender joints which in PsA seem less impacted by the current treatment regimes. ${ }^{24}$

Our observed high surgical rates at a population level is in alignment with an observational study from Norway by Nystad et $a l,{ }^{17}$ which do not detect a decrease in joint surgery even after the introduction of bDMARDS in 1999. It was speculated that it was too early to identify a change in surgical prognosis in patients in their cohort diagnosed from 1999 and onward. Lewinson et al explained an increase in surgery in the bDMARD era with better disease control in PsA unveiling coexisting osteoarthrosis which perhaps was augmented by higher healthcare surveillance in PsA patients.

Few studies have previously looked at the utilisation of joint surgery in PsA. In a single-centre study, Zangger et al found that $7 \%$ of a PsA cohort required surgery after a mean disease duration of 13.9 years. ${ }^{25}$ In comparison, our study showed that $15 \%$ needed surgery after 15 years.

In contrast, a cross-sectional study by Haque et al showed that $48 \%$ required surgical intervention at a mean disease duration of $1.6 \pm 12.1$ years. $^{26}$ The high proportion of patients who had surgery in that cohort may in part be generated by the inclusion of non-joint sacrificing surgery of more diagnostic than therapeutic impact such as diagnostic arthroscopy or other surgeries due to injuries not necessarily attributed to PsA pathophysiology. These types of surgery were excluded from our data, and in comparison, we found cumulative incidences of non-joint surgery of 3,12.5\% and $20 \%$ at 5, 10 and 15 years after diagnosis, respectively. The short mean disease duration before surgery found by Haque could be attributed to the fact that almost $27 \%$ of the surgery was done before the PsA diagnosis was established due to the cross-sectional design. A recent study by Lewinson et al found an increasing IR of arthroplasty in PsA from 1995 to $2010 .^{27}$ Our study also noticed an increase in arthroplasty around 2003 but opposed to Lewinson we then observed a decrease in IR especially in THA from 2003 which dropped slightly from 4.8 to 3.3 in 2012. We have no clear explanation for an increase in joint arthroplasty in 2001-2004, but a change in government in late 2001 and increased political focus on bringing down waiting lists for elective surgeries offer at least one potential explanation.

\section{Limitations}

In register-based studies, there is an intrinsic risk of misclassification bias which we tried to minimise by including only patients diagnosed at an inpatient or outpatient facility specialised in rheumatology or general internal medicine according to the DNPR. Using DNPR as a source register for identification of PsA is potentially biased towards a selection of more severe cases while patients with mild disease who are managed entirely at primary care units are not included. However, a previous study in Sweden, a country comparable to Denmark, have proven this to be a minor concern and would only increase the number of cases by $<4 \%$, and increase the degree of misclassification. ${ }^{28}$ Misclassification may have the potential to influence our findings by an increase in the completeness of diagnostic and surgical coding over time but we find temporal trends in misclassification unlikely to significantly have affected our results. Our design did not allow to adjust for risk factors such as osteoarthritis and fractures, and we did not have access to information on body mass index. Nevertheless, the purpose was also to give a descriptive account of the need for surgery in PsA.

The mean age at onset PsA in our cohort is at the beginning of the fifth decade and there is a risk that surgical rates may be influenced by age-related osteoarthritis but the high rate of surgery in PsA compared with GPC as presented in this study is still staggering even though the indication is osteoarthritis or erosive joint damage. The mean age for TKA and THA surgery with osteoarthritis as the indication is in Denmark 69 years, ${ }^{29}$ which is at the end of the sixth decade and in this context the PsA cohort in our study have a higher cumulative risk of surgery at a younger age. Because of the nature of observational studies, we cannot ascertain whether our results reflect changes in referral patterns, a shift in diagnostic focus, for example, the introduction of the CASPAR criteria. To investigate the impact of bDMARDs on the need for joint surgery, further studies using individual-level based information on DMARD treatment are needed.

\section{Strengths}

Our study benefits from a large nationwide population-based cohort of patients with PsA with access to complete 15 -year follow-up period which encompasses the outcome of the CsDMARD era and the beginning of the bDMARD era. We compared our results with age and gender-matched GPC to account for secular trends.

In conclusion, we found that the 5-year IR of joint related surgery in PsA did not change substantially from 1996 to 2012; however, during this period, the incidence remained twice as high as observed in matched GPCs. Thus, representing an important unmet need and treatment outcome to monitor in future studies. After 15 years of follow-up, 29\% of the PsA patients had received surgery.

Acknowledgements We wish to thank Christine Ballegaard at The Parker Institute for proofreading.

Contributors JG-M, RLC and LD had full access to all the data in the study and take responsibility for the integrity of the data and the accuracy of the data analysis. JG-M, RLC and LD: study concept and design. RLC and LD: acquisition of data. RLC: statistical analysis. All authors: interpretation of data; critical revision of the manuscript for important intellectual content. JG-M: drafting of the manuscript. LD and LEK: study supervision. 
Funding The study was funded by The Oak Foundation and Independent Research Fund Denmark (DFF-6110-00608).

Competing interests JG-M has received speaking fees from AbbVie, Eli Lilly and BK Ultrasound outside the present work. RLC has no competing interests. LEK has received fees for speaking and/or consultancy from Pfizer, AbbVie, Amgen, UCB, Celgene, BMS, Biogen, Sanofi, MSD, Novartis, Eli Lilly, Janssen Pharmaceuticals. LD has received speaking fees from UCB, MSD, Eli-Lilly and Janssen Pharmaceuticals outside the present work.

Patient consent for publication Not required.

Ethics approval According to Danish legislation, the registration and publication of data from national registers do not require patient consent or approval by Ethics Committees. Approval was given by the Danish Data Protection Agency (HGH-2017122, med I-Suite nr: 06047).

Provenance and peer review Not commissioned; externally peer reviewed.

Data availability statement No data are available.

\section{ORCID iDs}

Jørgen Guldberg-Møller http://orcid.org/0000-0002-6521-5825

Rene Lindholm Cordtz http://orcid.org/0000-0002-5271-2574

\section{REFERENCES}

1 Slobodin G, Rosner I, Rozenbaum M, et al. Psoriatic arthropathy: where now? Isr Med Assoc J 2009;11:430-4.

2 Gladman DD, Antoni C, Mease P, et al. Psoriatic arthritis: epidemiology, clinical features, course, and outcome. Ann Rheum Dis 2005;64(suppl_2):ii14-17.

3 Gladman DD, Day MS, Nam D, et al. Psoriatic arthritis. J Am Acad Orthop Surg 2005:20:118-23.

4 Alonso JCT, Perez AR, Castrillo JMA, et al. Psoriatic arthritis (PA): a clinical, immunological and radiological study of 180 patients. Rheumatology 1991;30:245-50.

5 Kristensen LE, Englund M, Neovius M, et al. Long-Term work disability in patients with psoriatic arthritis treated with anti-tumour necrosis factor: a population-based regional Swedish cohort study. Ann Rheum Dis 2013;72:1675-9.

6 Kristensen LE, Jørgensen TS, Christensen R, et al. Societal costs and patients' experience of health inequities before and after diagnosis of psoriatic arthritis: a Danish cohort study. Ann Rheum Dis 2017;76:1495-501.

7 Rahman P, Nguyen E, Cheung C, et al. Comparison of radiological severity in psoriatic arthritis and rheumatoid arthritis. J Rheumatol 2001;28:1041-4.

8 Kingsley GH, Kowalczyk A, Taylor H, et al. A randomized placebo-controlled trial of methotrexate in psoriatic arthritis. published online first: 10AD.

9 Eder L, Thavaneswaran A, Chandran V, et al. Tumour necrosis factor $\alpha$ blockers are more effective than methotrexate in the inhibition of radiographic joint damage progression among patients with psoriatic arthritis. Ann Rheum Dis 2014:73:1007-11.

10 Antoni C, Krueger GG, de Vlam K, et al. Infliximab improves signs and symptoms of psoriatic arthritis: results of the impact 2 trial. Ann Rheum Dis 2005;64:1150-7.

11 Mease PJ, Ory P, Sharp JT, et al. Adalimumab for long-term treatment of psoriatic arthritis: 2-year data from the adalimumab effectiveness in psoriatic arthritis trial (ADEPT) 2008.
12 Sterry W, Ortonne J-P, Kirkham B, et al. Comparison of two etanercept regimens for treatment of psoriasis and psoriatic arthritis: PRESTA randomised double blind multicentre trial. BMJ 2010;340.

13 Kristensen LE, Gülfe A, Saxne T, et al. Efficacy and tolerability of anti-tumour necrosis factor therapy in psoriatic arthritis patients: results from the South Swedish arthritis treatment group register. Ann Rheum Dis 2008:67:364-9.

14 Cordtz RL, Hawley S, Prieto-Alhambra D, et al. Incidence of hip and knee replacement in patients with rheumatoid arthritis following the introduction of biological DMARDs: an interrupted time-series analysis using nationwide Danish healthcare registers. Ann Rheum Dis 2018:77:684-9.

15 Egeberg A, Kristensen LE, Thyssen JP, et al. Incidence and prevalence of psoriatic arthritis in Denmark: a nationwide register linkage study. Ann Rheum Dis 2017;76:1591-7.

16 Glintborg B, Østergaard M, Dreyer L, et al. Treatment response, drug survival, and predictors thereof in 764 patients with psoriatic arthritis treated with anti-tumor necrosis factor $\alpha$ therapy: results from the nationwide Danish DANBIO registry. Arthritis Rheum 2011;63:382-90.

17 Nystad TW, Husum YS, Furnes ON, et al. Incidence and predictive factors for orthopedic surgery in patients with psoriatic arthritis. J Rheumatol 2018:45:1532-40.

18 Nicholls S, Langan S, Sørensen HT, et al. The record reporting guidelines: meeting the methodological and ethical demands of transparency in research using routinelycollected health data. Clin Epidemiol 2016;8:389-92.

19 Schmidt M, Pedersen L, Sørensen HT. The Danish civil registration system as a tool in epidemiology. Eur J Epidemio/ 2014;29:541-9.

20 NOMESCO. Classification of surgical procedures. version 115 2011: no.93. Copenhagen, 2010.

21 Aaalen O, Johansen S. An empirical transition matrix for non-homogeneous Markov chains based on censored observations. Scand J Stat 1978.

22 Jørgensen T, Dreyer L, Guðbjörnsson B. Prescription patterns of tumour necrosis factor inhibitor and ustekinumab in psoriatic arthritis: a Nordic population-based cohort study. Ann Rheum Dis 2017;76.

23 Coates LC, Navarro-Coy N, Brown SR, et al. The TICOPA protocol (tight control of psoriatic arthritis): a randomised controlled trial to compare intensive management versus standard care in early psoriatic arthritis. BMC Musculoskelet Disord 2013;14:101.

24 Højgaard P, Christensen R, Dreyer L, et al. Pain mechanisms and ultrasonic inflammatory activity as prognostic factors in patients with psoriatic arthritis: protocol for a prospective, exploratory cohort study. BMJ Open 2016;6:e010650.

25 Zangger P, Gladman DD, Bogoch ER. Musculoskeletal surgery in psoriatic arthritis. J Rheumatol 1998:25:725-9.

26 Haque N, Lories RJ, de Vlam K. Orthopaedic interventions in patients with psoriatic arthritis: a descriptive report from the SPAR cohort. RMD Open 2016;2.

27 Lewinson RT, Vallerand IA, LaMothe JM, et al. Increasing rates of arthroplasty for psoriatic arthritis in the United Kingdom between 1995 and 2010. Arthritis Care Res.

28 Jordan KP, Jöud A, Bergknut C, et al. International comparisons of the consultation prevalence of musculoskeletal conditions using population-based healthcare data from England and Sweden. Ann Rheum Dis 2014;73:212-8.

29 Cordtz RL, Højgaard P, Zobbe K, et al. Predictors of revision, prosthetic joint infection and mortality following total hip or total knee arthroplasty in patients with rheumatoid arthritis: a nationwide cohort study using Danish healthcare registers. Ann Rheum Dis 2019;77:281-8. 